\title{
Epigallocatechin-3-gallate prevents tumor cell implantation/ growth in an experimental rat bladder tumor model
}

\author{
JERZY JANKUN, RICK W. KECK and STEVEN H. SELMAN \\ Urology Research Center, Department of Urology, College of Medicine, University of Toledo, Toledo, OH 43614, USA
}

Received August 22, 2013; Accepted October 4, 2013

DOI: 10.3892/ijo.2013.2174

\begin{abstract}
The aim of this study was to determine the efficacy of epigallocatechin-3-gallate (EGCG) (Polyphenon $\mathrm{E}^{\circledR}$ ) in comparison with mitomycin $\mathrm{C}(\mathrm{MMC})$ to prevent tumor cell implantation/growth in an animal model of superficial bladder cancer and search for possible mechanism(s) of action. Female Fisher 344 rats were used to study the effects of EGCG and mitomycin $\mathrm{C}$ for the prevention of transitional cell tumor implantation (AY-27). Twenty rats served as a control, tumor implantation and saline wash only. Sixty rats were treated with EGCG $(100,200$ and $400 \mu \mathrm{M})$ intravesically for 60 or $120 \mathrm{~min}$ after tumor implantation. Thirty other rats were divided equally and pretreated with $400 \mu \mathrm{M}$ EGCG or saline for $120 \mathrm{~min}$ before tumor initiation. In a separate series of experiments, 30 rats were treated 2 weeks after tumor initiation with saline or EGCG $(400 \mu \mathrm{M})$. In a different experiment 39 rats were treated with: saline $(\mathrm{n}=10) \mathrm{EGCG}(\mathrm{n}=9) 400 \mu \mathrm{M}, \mathrm{MMC}$ $(\mathrm{n}=10) 0.5 \mu \mathrm{M}, \mathrm{MMC}(\mathrm{n}=10) 400 \mu \mathrm{M}$. Rats were sacrificed 3 weeks following treatment. Gross and histological analyses were performed on the bladders. EGCG and mitomycin C prevented intravesical tumor growth in a concentration- and time-dependent manner. EGCG pretreatment or treatment 2 weeks post tumor implantation did not have therapeutic effects. Molecular modeling suggests that EGCG inhibits urokinase and matrix metalloproteinase-9. EGCG prevents intravesical tumor implantation/growth with a slightly better efficacy than mitomycin $\mathrm{C}$ in this experimental model. The data suggest that EGCG lowers proteolytic activity and lowers probability of cancer cell implantation rather than direct cancer cell killing.
\end{abstract}

\section{Introduction}

Bladder cancer is the fourth leading cause of cancer in American men. The majority of bladder cancers present as

Correspondence to: Professor Jerzy Jankun, Urology Research Center, Department of Urology, Mail Stop 1091, Health Science Campus, The University of Toledo, 3000 Arlington, Toledo, $\mathrm{OH}$ 43614-2598, USA

E-mail: jerzy.jankun@utoledo.edu

Key words: bladder cancer, epigallocatechin-3-gallate, mitomycin $\mathrm{C}$, urokinase, membrane metalloproteinase superficial disease, restricted to the bladder mucosa or submucosal layer. Most superficial tumors (60-70\%) have a tendency for recurrence after transurethral resection of a bladder tumor and $15-25 \%$ are at high risk for progression to muscle invasion. Tumor implantation at tumor resection site may account in part for the high rate of tumor recurrence $(1,2)$. People who are at risk of recurrence will have either intravesical chemotherapy, most commonly mitomycin $\mathrm{C}$ or Bacillus Calmette-Guérin (BCG) $(3,4)$. None of these agents have proved to fully prevent disease progression and have some side effects (3).

Numerous pre-clinical and clinical studies have presented convincing evidence that green tea may protect against cancer $(5,6)$. Green tea extract contains catechins such as epigallocatechin-3-gallate (EGCG), epigallocatechin, epicatechin gallate and epicatechin and the anticarcinogenic properties of green tea are attributed to the biological activities of these polyphenol components. EGCG is the most abundant component and the most widely studied (5,7-9). EGCG has been shown to induce apoptosis, inhibit cancer cell proliferation, and inhibit invasion and metastasis of cancers (10-14). This polytrophic molecule affects many different pathways altering expression and activity of numerous proteins (15).

Matrix dissolution is an essential step during carcinogenesis where matrix metalloproteinase (MMP-9) and urokinase (uPA) are one of the most important proteases functioning during invasion and tumor spread $(16,17)$. Expression and activity of both enzymes are inhibited by EGCG.

MMPs are a family of zinc-dependent endopeptidases which are involved in the breakdown of extracellular matrix. Among MMPs, MMP-9 (gelatinase B) has gained attention for its role in tumor invasion and metastasis, since MMP-9 has an exceptional ability to degrade type IV collagen, a major constituent of the basement membrane. Accordingly, elevated expression of MMP-9 has been associated with increased metastatic potential in many cancer types (18). Furthermore, direct inhibition of MMP-9 activity or suppression of the expression via blockage of the ERK-MAP kinase pathway results in the inhibition of tumor invasion and metastasis (18-21). It has been found that green tea polyphenol epigallocatechin-3-gallate (EGCG) inhibits tumor invasion and implantation by directly inhibiting the MMP-9 activity $(11,12,18)$ and suppressing the ERK-MAP kinase pathway (22).

Urokinase activates plasminogen to plasmin an enzyme that degrades extracellular matrix enabling cancer cells to invade and metastasize $(23,24)$. Similarly to MMP-9, inhibi- 
tion of uPA results in inhibition of cancer cell implantation, invasion and metastasis $(8,13,23-25)$. EGCG inhibits expression of uPA most likely by suppression of $\mathrm{NF \kappa B}(26,27)$ and urokinase activity $(13-15,27)$. Consequently, the inhibition of MMP and UPA expression and/or activity by EGCG signifies potential novel therapeutic strategies for the treatment of cancer patients.

We evaluated EGCG as an intravesical agent for the prevention of transitional cell tumor implantation in the past. We previously found that intravesical instillation of EGCG inhibits the growth of AY-27 rat transitional cells implanted in this model $(1,28)$. In the current study we evaluated a large number of animals treated with different doses of EGCG or mitomycin $\mathrm{C}$ and propose a possible mechanism of action.

\section{Materials and methods}

Cell line. AY-27 rat urothelial derived tumor cells (29) were maintained in RPMI-1640 medium with $100 \mathrm{U} / \mathrm{ml}$ penicillin and $100 \mu \mathrm{g} / \mathrm{ml}$ streptomycin (Sigma-Aldrich ${ }^{\circledR}$ ), and 10\% FBS (Atlanta Biologicals ${ }^{\circledR}$, Lawrenceville, GA, USA).

Animals. All experiments using animals in this study were approved by the University of Toledo institutional animal care and use committee and performed under the guidance of the Department of Laboratory Animal Resources. Female Fischer 344 rats (Charles River ${ }^{\circledR}$, Wilmington, MA, USA) were used in conjunction with the transplantable AY-27 rat bladder tumor cell line.

Tumor initiation. Tumor growth was initiated in the rat bladder by injuring the bladder mucosa and immediately instilling a suspension of AY-27 tumor cells obtained from stock cultures. Surgical exposure of the bladder was necessary to ensure proper placement of the cautery and visualization of the cauterization procedure under general anesthesia. A blunt tipped 24-gauge copper wire was advanced through the catheter. Six hundred volts current ( $60 \mathrm{~W}$ maximum) was used to cauterize the bladder wall, creating a small white puckered area. The bladder was catheterized with an 18-gauge Teflon i.v. catheter allowing easy access to the bladder lumen for cauterization, instillation of the tumor cells and treatment solutions. The concentration of the EGCG and MMC treatment solutions was up to $400 \mu \mathrm{M}$. After mucosal injury a suspension of tumor cells in RPMI media $\left(1 \times 10^{6}\right.$ cells $\left./ 0.5 \mathrm{ml}\right)$ was instilled into the bladder. The tumor cell suspension remained in the bladder for $30 \mathrm{~min}$. Small tumors were palpable within 2-3 weeks.

Treatment solutions. Treatment solutions were prepared by diluting MMC and EGCG in a $0.9 \%$ normal saline solution. The EGCG concentration of treatment solutions were based on the total EGCG content (63\%) in the PE used. EGCG and NS control solutions were adjusted to $\mathrm{pH} 5.0, \mathrm{pH}$ of EGCG in the highest concentration.

Animal treatment. Phase 1 consisted of 8 groups (80 animals, 10 rats/group). Bladders of groups I and II $(n=10)$, the control groups, were instilled with a $0.9 \%$ normal saline solution. Dwell time for group I was $60 \mathrm{~min}$ and $120 \mathrm{~min}$ for group II. Groups III ( $\mathrm{n}=10$, dwell time $60 \mathrm{~min})$ and IV $(\mathrm{n}=10$, dwell time
$120 \mathrm{~min}$ ) bladders were instilled with a $100-\mu \mathrm{M}$ concentration of PE. Groups V ( $\mathrm{n}=10$, dwell time $60 \mathrm{~min})$ and VI $(\mathrm{n}=10$, dwell time $120 \mathrm{~min}$ ) bladders were instilled with a $200-\mu \mathrm{M}$ concentration of PE. Groups VII ( $\mathrm{n}=10$, dwell time $60 \mathrm{~min}$ ) and VIII ( $\mathrm{n}=10$, dwell time $120 \mathrm{~min}$ ) bladders were instilled with a $400-\mu \mathrm{M}$ concentration of EGCG. All rats in phase 1 were euthanized 3 weeks after tumor initiation for direct examination of the bladder to determine the incidence of tumor growth.

Phase 2 of the in vivo study investigated the potential effectiveness of EGCG as a pretreatment prior to bladder injury and instillation of AY-27 tumor cells. This phase consisted of 2 groups; a control group, group IX $(n=15)$ was pretreated with a $0.9 \%$ normal saline solution, group $X(n=15)$ was pretreated with $400 \mu \mathrm{M}$ of EGCG for $120 \mathrm{~min}$. The bladders were instilled with $0.5 \mathrm{ml}$ of treatment solution and then were gently emptied after the first $60 \mathrm{~min}$ and re-filled with fresh treatment solution for the remaining $60 \mathrm{~min}$. Thirty minutes after the treatment time with PE or saline, the tumor initiation process, as described above in phase 1 was performed. All rats in phase 2 were euthanized 3 weeks after tumor initiation for direct examination of the bladder to determine the incidence of tumor growth.

Phase 3 of the in vivo study investigated the potential effectiveness of PE as a treatment after establishment of early stage bladder cancer. The bladder tumor initiation process, as described above in phase 1 was performed on 30 rats. Two weeks after tumor initiation the rats were divided into 2 groups of 15 rats each. Rats in group XI $(n=15)$, or the control group, had their bladders instilled with saline for $120 \mathrm{~min}$. The treatment group, group XII $(n=15)$ had their bladders instilled with $400 \mu \mathrm{M}$ of EGCG for $120 \mathrm{~min}$. After the first $60 \mathrm{~min}$, the bladders were emptied and refilled with control or treatment solution for the remaining $60 \mathrm{~min}$.

Phase 4 consisted of four groups. Thirty minutes post bladder injury and tumor cell instillation, the tumor cell suspension was gently expelled and the bladders were instilled with $0.5-1.0 \mathrm{ml}$ of the treatment solution. Group XIII $(\mathrm{n}=10)$, or the control group, involved the instillation of a $0.9 \%$ normal saline solution. Group XIV $(n=10)$ involved the instillation of $400 \mu \mathrm{M}$ EGCG. Group XV (n=9) involved the instillation of $0.5 \mu \mathrm{M}$ of MMC and group XVI $(\mathrm{n}=10)$ involved the instillation of $400 \mu \mathrm{M}$ of MMC. The dwell time for all groups was $2 \mathrm{~h}$; the bladders were gently emptied after the first $60 \mathrm{~min}$ and re-filled with fresh treatment solution for the remaining $60 \mathrm{~min}$. At the end of the treatment time the bladders were gently expressed and gently rinsed with normal saline. All rats in phase 4 were euthanized 4 weeks after treatment for direct examination of the bladder.

All animals were euthanized by $\mathrm{CO}_{2}$ inhalation. The bladders were removed, fixed in $10 \%$ phosphate-buffered formalin for $24 \mathrm{~h}$ and then bisected. The bladders were examined grossly and photographed. The bladders were removed, placed in $10 \%$ phosphate-buffered formalin solution and fixed. They were hemisected with a razor, examined under $\mathrm{x} 4$ magnification and sent for histopathological sectioning.

Molecular modeling. Two dimensional structure of EGCG was created by AccelrysDraw v. 4.0 in 'skc' format. 2D structure was converted into three dimensional and 'pdb' format file 

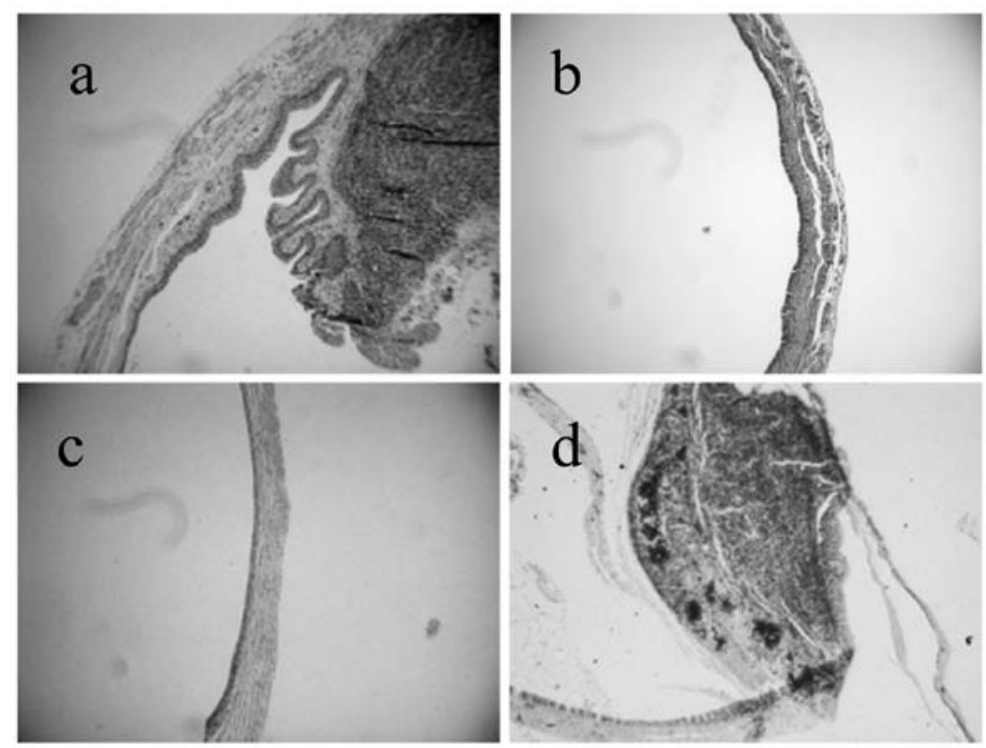

Figure 1. Typical microscopic appearance (reduced from $\mathrm{x} 40$ ) of: (a) control bladder with tumors; (b) tumor-free bladder treated with $400 \mu \mathrm{M}$ of EGCG; (c) tumor-free bladder treated with $400 \mu \mathrm{M}$ of MMC; (d) bladder with tumors treated with $400 \mu \mathrm{M}$ of MMC.

by web based program (http://www.molecular-networks.com/ products). Dockings of EGCG to proteins were done by VINA Autodock (30). Protein structures and DNA sequences were downloaded from http://www.rcsb.org/pdb/home/home.do as: 2ovx - MMP-9 (31), 2vnt - urokinase (32). Search box was set up with following parameters for: MMP-9 (center: $x=27$, $y=6, z=51$; size: $x=40, y=56, z=40$ ), urokinase (center: $\mathrm{x}=-37, \mathrm{y}=171, \mathrm{z}=70$; size: $\mathrm{x}=40, \mathrm{y}=40, \mathrm{z}=40$ ). Inhibitors present in pdb structures were used to determine center of search and later removed from structure. Small molecules were kept flexible by allowing rotation around single bonds. By default, VINA Autodock analyzes eight different protein/ inhibitor complexes (different conformers and the one with the lowest free energy is considered the most probable. Free energy can be converted to $\mathrm{K}_{\mathrm{i}}$ by the below formula (30,33-36):

$$
\mathrm{K}_{\mathrm{i}}=\exp (\Delta \mathrm{G} /(\mathrm{R} * \mathrm{~T}))
$$

The final analyses of structures generated by Autodock and figures generation were done utilizing PyMOL v. 1.4. $(37,38)$. DNA sequences were downloaded from databases $(39,40)$.

Statistical analysis. Tumor implantation and growth between the groups was assessed by Fisher's 2-way exact test.

\section{Results}

In vivo studies. Overall similarity between human and rat uPA is $77 \%$ and differs by two amino acids in specificity pocket where uPA inhibitors bind $(8,13,39)$ and $79 \%$ similarity in case of MMP-9 (40). Thus we expect that data collected on rats will be applicable in humans.

Tumor growth was observed in both control groups (100\%) (Table I). While concentration of EGCG and time of treatment increases, tumor growth ratio decreases, statistically significant in comparison with control (groups IV-VIII, $\mathrm{p} \leq 0.03$ ). In highest concentration of EGCG and longest time of treatment we observed no tumor growth at all in 10 of 10 animals
Table I. Tumor growth in animals of control group and treated with different concentration of EGCG as a function of time.

\begin{tabular}{lrrr}
\hline Group & $\begin{array}{r}\text { EGCG } \\
\text { in } \mu \mathrm{M}\end{array}$ & $\begin{array}{c}\text { Dwell time } \\
(\mathrm{min})\end{array}$ & $\begin{array}{c}\text { Tumor growth } \\
\text { ratio }\end{array}$ \\
\hline I & 0 & 60 & $10 / 10$ \\
II & 0 & 120 & $10 / 10$ \\
III & 100 & 60 & $7 / 10$ \\
IV & 100 & 120 & $5 / 10$ \\
V & 200 & 60 & $4 / 10$ \\
VI & 200 & 120 & $2 / 10$ \\
VII & 400 & 60 & $2 / 10$ \\
VIII & $\mathbf{4 0 0}$ & $\mathbf{1 2 0}$ & $\mathbf{0} / \mathbf{1 0}$ \\
\hline
\end{tabular}

Table II. Tumor growth ratios in animals pretreated with EGCG.

\begin{tabular}{lrcc}
\hline Group & $\begin{array}{r}\text { EGCG } \\
\text { in } \mu \mathrm{M}\end{array}$ & $\begin{array}{c}\text { Dwell time } \\
\text { (min) }\end{array}$ & $\begin{array}{c}\text { Tumor growth } \\
\text { ratio }\end{array}$ \\
\hline IX & 0 & 120 & $14 / 15$ \\
X & 400 & 120 & $15 / 15$ \\
\hline
\end{tabular}

$(\mathrm{p}<0.0001)$. Pretreat animals with EGCG demonstrated $100 \%$ tumor growth (phase 2, Table II). Similarly, there was no effect on tumor growth in group of animals treated with EGCG 2 weeks after establishment of early stage bladder cancer, all 15 animals had tumor growth (phase 3, Table III). In phase 4 animals were treated with EGCG and MMC (Table IV). A statistically significant difference was seen between: control and EGCG treated $(\mathrm{p}<0.0001)$, control and MMC treated groups (400 $\mu \mathrm{M}, \mathrm{p}<0.0007 ; 0.5 \mu \mathrm{M} \mathrm{p}<0.0325)$. 
Table III. Tumor growth ratios, treated with EGCG 2 weeks post tumor initiation.

\begin{tabular}{lccc}
\hline Group & $\begin{array}{c}\text { EGCG } \\
\text { in } \mu \mathrm{M}\end{array}$ & $\begin{array}{c}\text { Dwell time } \\
(\mathrm{min})\end{array}$ & $\begin{array}{c}\text { Tumor growth } \\
\text { ratio }\end{array}$ \\
\hline XI & 0 & 120 & $15 / 15$ \\
XII & 400 & 120 & $15 / 15$ \\
\hline
\end{tabular}

Table IV. Tumor growth ratios in animals treated with EGCG and MMC.

\begin{tabular}{llcc}
\hline Group & $\begin{array}{c}\text { Treatment } \\
\text { solution }\end{array}$ & $\begin{array}{c}\text { Concentration } \\
(\mu \mathrm{M})\end{array}$ & $\begin{array}{c}\text { Tumor growth } \\
\text { ratio }\end{array}$ \\
\hline XIII & NS & 0 & $10 / 10$ \\
XIV & EGCG & $\mathbf{4 0 0}$ & $\mathbf{0 / 9}$ \\
XV & MMC & 0.5 & $5 / 10$ \\
XVI & MMC & 400 & $2 / 10$ \\
\hline
\end{tabular}

Molecular modeling. Fig. 2 shows that EGCG occupies space where MMP-9 inhibitor 5-(4-phenoxyphenyl)-5-(4-pyrimidin2-ylpiperazin-1-yl)pyrimidine-2,4,6(2h,3h)-trione is present (31). Calculated affinity of EGCG is $-8.1 \mathrm{kcal} / \mathrm{M}$ or $1.20 \mu \mathrm{M}$.

EGCG is located in the specificity pocket of urokinase superimposed over uPA inhibitor: 1-(\{4-chloro-1-[(diamino-

a
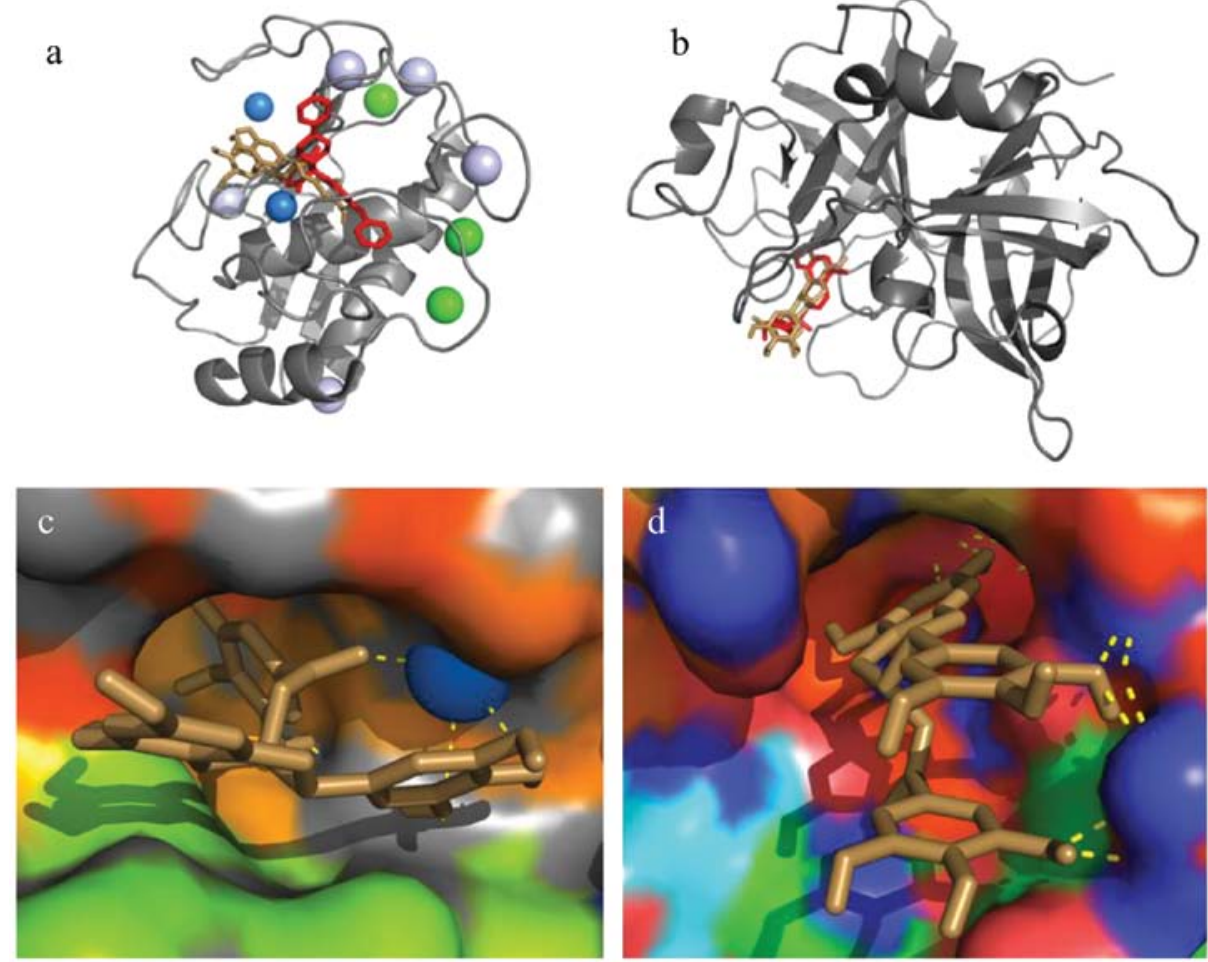

methylidene)amino]isoquinolin-7-yl\}sulfonyl)-d-proline (32). Calculated affinity of EGCG to uPA is $-7.9 \mathrm{kcal} / \mathrm{M}$ or $1.67 \mu \mathrm{M}$.

\section{Discussion}

Prediction of disease outcome in superficial transitional cell carcinoma of the bladder in an individual patient is still impossible. It has been recommended that in patients the initial treatment, transurethral resection of bladder tumor (TURBT) should be followed by immediate intravesical instillation with mitomycin $\mathrm{C}$ to prevent a tumor cell implantation during TURBT. Drug efficacy has been clearly demonstrated in short term, but the long term effects remain a question $(41,42)$. Therefore, there exist a need for a novel agent to be used as an adjunct to endoscopic bladder tumor resection.

Wang et al observed a protective effect on bladder cancer in group of green tea drinkers of Asian people, but did not proposed the biological mechanism (43). Contrary to that $\mathrm{Wu}$ et al found no relationship between drinking green tea and bladder cancer risk (44) despite numerous reports on cancer preventing effects of EGCG in vitro and in vivo (45-47). That may be related to fact that the concentrations of EGCG used in some in vitro and in vivo experiments (20-100 $\mu \mathrm{M})$ are much higher than the plasma and tissue concentrations observed in humans after drinking a few cups of green tea (mostly $<0.5 \mu \mathrm{M})(48)$. An additional complicating factor in assessment of effects of EGCG on bladder cancer is consumption of large amounts of fruits and vegetables by Asian population. Kamat and Lamm found that even in a high-risk group such as nuclear-bomb survivors in Japan, high consumption of vegetables and fruits is protective against bladder cancer (49).

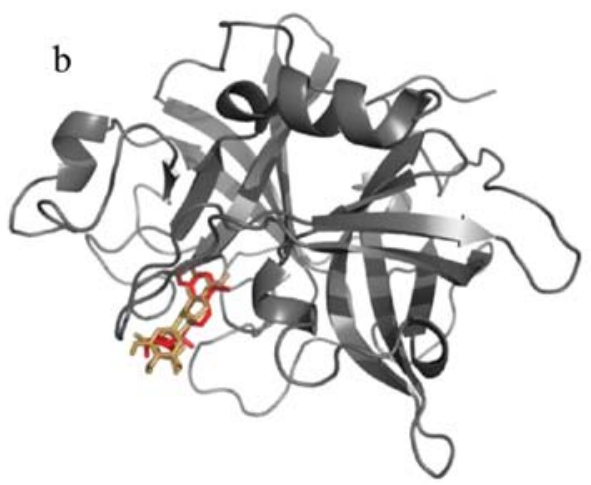

Figure 2. Ribbon model of: (a) MMP-9/inhibitrors; (b) uPA/inhibitors; surface of active site of: (c) MMP-9; (d) uPA. Inhibitors of MMP-9 and uPA are shown as sticks in red. EGCG is shown as stick model in light brown. Ions in MMP-9 are shown as speres: $\mathrm{Zn}^{2+}$ in blue, $\mathrm{Ca}^{2+}$ in light blue, $\mathrm{Cl}^{-}$in green. Polar contacts are shown as a yellow doted lines. 
Intravesical instillation EGCG into bladder permits choice of concentration and time of treatment and is free of these uncertainties. Kemberling et al (1) observed cell lethality of the AY-27 cell line at concentrations $>100 \mu \mathrm{M}$. In the same study they found that intravesical instillation of EGCG inhibits the growth of AY-27 rat transitional cells implanted in Fisher rats. Selman and Keck studied EGCG and mitomycin $\mathrm{C}$ and on their in vitro and in vivo effects using AY-27 cells. They found that at $72 \mathrm{~h}$ after exposure to MMC there was $100 \%$ lethality at all doses $>30 \mu \mathrm{M}$, treatment with EGCG reduces the number of AY-27 cells by $\sim 80 \%$ at the $200-$ and $400-\mu \mathrm{M}$ concentrations. In vivo studies using the same animal model there was $100 \%$ tumor growth in control treated animals (10 of 10), no tumor growth after 4 weeks in animals treated with EGCG (0 of 10) and no tumor growth in 8 of 10 animals treated with MMC (28). This study is continuation of our previous experiments done in the same laboratory on larger number of animals and in different concentrations of EGCG and MMC. We found the same results as previously for highest concentration of EGCG (tumor-free in 9 of 9 animals) and MMC (tumor-free in 8 of 10 animals). This raises the question why MMC superior in cell killing in the cell culture is inferior to EGCG in animal studies. Both are lethal to cancer cells but it seems that some other mechanism is more relevant in this case. One of the possibilities is that EGCG prevents cancer cell implantation into the bladder wall. As we stated in the introduction EGCG inhibits MMP-9 and UPA proteolytic enzymes critical for cell implantation. Maeda-Yamamoto et al reported that EGCG inhibited completely MMP-9 activity at concentration of $40 \mu \mathrm{M}$ (50) while Demeule et al reported that EGCG inhibited $80 \%$ activity at concentration of $30 \mu \mathrm{M}(51)$. Our molecular modeling calculations provides evidence that EGCG binds to the active site as a competitive inhibitor with $\mathrm{Ki}$ within range reported above. EGCG inhibits uPA activity in the $\mu \mathrm{M}$ level and the molecular modeling calculation also suggest competitive mechanism in the $\mu \mathrm{M}$ range (13-15). There are some reports that EGCG down regulates expression of both proteases $(11,12,15,51-54)$. End result will be the same, lower proteolytic activity and less probable cancer cell implantation. However, this mechanism seems to be less probable since treatment was limited to two hours and these proteases are already synthetized in cancer cells.

Our data show the slightly better effects of EGCG than $\mathrm{MMC}$ in this experimental model. Since mitomycin $\mathrm{C}$ requires special precautions during handling and has side effects $(55,56)$ we propose use of EGCG as an agent to decrease tumor cell implantation and consequent intravesical cancer growth in a bladder. EGCG is a potential novel therapeutic strategy for its use as an adjunct to endoscopic bladder tumor resection.

\section{Acknowledgements}

This study was supported in part by grant from Frank Stranahan Endowed Chair.

\section{References}

1. Kemberling JK, Hampton JA, Keck RW, Gomez MA and Selman SH: Inhibition of bladder tumor growth by the green tea derivative epigallocatechin-3-gallate. J Urol 170: 773-776, 2003.
2. Weldon TE and Soloway MS: Susceptibility of urothelium to neoplastic cellular implantation. Urology 5: 824-827, 1975.

3. Amling CL: Diagnosis and management of superficial bladder cancer. Curr Probl Cancer 25: 219-278, 2001.

4. Resnick MJ, Bassett JC and Clark PE: Management of superficial and muscle-invasive urothelial cancers of the bladder. Curr Opin Oncol 25: 281-288, 2013.

5. Ho YC, Yang SF, Peng CY, Chou MY and Chang YC: Epigallocatechin-3-gallate inhibits the invasion of human oral cancer cells and decreases the productions of matrix metalloproteinases and urokinase-plasminogen activator. J Oral Pathol Med 36: 588-593, 2007.

6. Rogers AE, Hafer LJ, Iskander YS and Yang S: Black tea and mammary gland carcinogenesis by 7,12-dimethylbenz[a]anthracene in rats fed control or high fat diets. Carcinogenesis 19: 1269-1273, 1998

7. Jankun J, Al-Senaidy A and Skrzypczak-Jankun E: Can inactivators of plasminogen activator inhibitor alleviate the burden of obesity and diabetes (Review)? Int J Mol Med 29: 3-11, 2012.

8. Jankun J, Selman SH, Aniola J and Skrzypczak-Jankun E: Nutraceutical inhibitors of urokinase: potential applications in prostate cancer prevention and treatment. Oncol Rep 16: 341-346, 2006.

9. Stoner GD and Mukhtar H: Polyphenols as cancer chemopreventive agents. J Cell Biochem (Suppl) 22: 169-180, 1995.

10. Deng YT and Lin JK: EGCG inhibits the invasion of highly invasive CL1-5 lung cancer cells through suppressing MMP-2 expression via JNK signaling and induces G2/M arrest. J Agric Food Chem 59: 13318-13327, 2011.

11. Garbisa S, Biggin S, Cavallarin N, Sartor L, Benelli R and Albini A: Tumor invasion: molecular shears blunted by green tea. Nat Med 5: 1216, 1999.

12. Garbisa S, Sartor L, Biggin S, Salvato B, Benelli R and Albini A: Tumor gelatinases and invasion inhibited by the green tea flavanol epigallocatechin-3-gallate. Cancer 91: 822-832, 2001.

13. Jankun J, Selman SH, Swiercz R and Skrzypczak-Jankun E: Why drinking green tea could prevent cancer. Nature 387: 561, 1997.

14. Singh BN, Shankar S and Srivastava RK: Green tea catechin, epigallocatechin-3-gallate (EGCG): mechanisms, perspectives and clinical applications. Biochem Pharmacol 82: 1807-1821, 2011.

15. Beltz LA, Bayer DK, Moss AL and Simet IM: Mechanisms of cancer prevention by green and black tea polyphenols. Anticancer Agents Med Chem 6: 389-406, 2006.

16. Boissier S, Ferreras M, Peyruchaud O, et al: Bisphosphonates inhibit breast and prostate carcinoma cell invasion, an early event in the formation of bone metastases. Cancer Res 60: 2949-2954, 2000 .

17. Lah TT, Duran Alonso MB and Van Noorden CJ: Antiprotease therapy in cancer: hot or not? Expert Opin Biol Ther 6: 257-279, 2006.

18. Tanimura S, Kadomoto R, Tanaka T, Zhang YJ, Kouno I and Kohno M: Suppression of tumor cell invasiveness by hydrolyzable tannins (plant polyphenols) via the inhibition of matrix metalloproteinase-2/-9 activity. Biochem Biophys Res Commun 330: 1306-1313, 2005.

19. Park JW, Hong JS, Lee KS, Kim HY, Lee JJ and Lee SR: Green tea polyphenol (-)-epigallocatechin gallate reduces matrix metalloproteinase-9 activity following transient focal cerebral ischemia. J Nutr Biochem 21: 1038-1044, 2010.

20. Roomi MW, Monterrey JC, Kalinovsky T, Rath M and Niedzwiecki A: Comparative effects of EGCG, green tea and a nutrient mixture on the patterns of MMP-2 and MMP-9 expression in cancer cell lines. Oncol Rep 24: 747-757, 2010.

21. Sen T and Chatterjee A: Epigallocatechin-3-gallate (EGCG) downregulates EGF-induced MMP-9 in breast cancer cells: involvement of integrin receptor $\alpha 5 \beta 1$ in the process. Eur J Nutr 50: 465-478, 2011.

22. Chung JY, Park JO, Phyu H, Dong Z and Yang CS: Mechanisms of inhibition of the Ras-MAP kinase signaling pathway in 30.7b Ras 12 cells by tea polyphenols (-)-epigallocatechin-3-gallate and theaflavin-3,3'-digallate. FASEB J 15: 2022-2024, 2001.

23. Swiercz R, Keck RW, Skrzypczak-Jankun E, Selman SH and Jankun J: Recombinant PAI-1 inhibits angiogenesis and reduces size of LNCaP prostate cancer xenografts in SCID mice. Oncol Rep 8: 463-470, 2001.

24. Swiercz R, Skrzypczak-Jankun E, Merrell MM, Selman SH and Jankun J: Angiostatic activity of synthetic inhibitors of urokinase type plasminogen activator. Oncol Rep 6: 523-526, 1999. 
25. Miyake K, Shimada M, Nishioka M, et al: Downregulation of matrix metalloprotease-9 and urokinase plasminogen activator by TX-1877 results in decreased tumor growth and metastasis on xenograft model of rectal cancer. Cancer Chemother Pharmacol 64: 885-892, 2009.

26. Jiang J, Eliaz I and Sliva D: Suppression of growth and invasive behavior of human prostate cancer cells by ProstaCaid: mechanism of activity. Int J Oncol 38: 1675-1682, 2011.

27. Shankar S, Ganapathy S and Srivastava RK: Green tea polyphenols: biology and therapeutic implications in cancer. Front Biosci 12: 4881-4899, 2007.

28. Selman SH and Keck RW: A comparative study of the inhibiting effects of mitomycin $\mathrm{C}$ and polyphenolic catechins on tumor cell implantation/growth in a rat bladder tumor model. J Urol 186: 702-706, 2011 .

29. Xiao Z, McCallum TJ, Brown KM, et al: Characterization of a novel transplantable orthotopic rat bladder transitional cell tumour model. Br J Cancer 81: 638-646, 1999.

30. Trott $\mathrm{O}$ and Olson AJ: AutoDock Vina: improving the speed and accuracy of docking with a new scoring function, efficient optimization, and multithreading. J Comput Chem 31: 455-461, 2010.

31. Tochowicz A, Maskos K, Huber R, et al: Crystal structures of MMP-9 complexes with five inhibitors: contribution of the flexible Arg424 side-chain to selectivity. J Mol Biol 371: 989-1006, 2007

32. Fish PV, Barber CG, Brown DG, et al: Selective urokinase-type plasminogen activator inhibitors. 4. 1-(7-sulfonamidoisoquinolinyl)guanidines. J Med Chem 50: 2341-2351, 2007.

33. Bikadi Z, Hazai E,Zsila F and Lockwood SF: Molecular modeling of non-covalent binding of homochiral ( $3 \mathrm{~S}, 3$ 'S)-astaxanthin to matrix metalloproteinase-13 (MMP-13). Bioorg Med Chem 14: 5451-5458, 2006.

34. D'Hoedt D and Bertrand D: Nicotinic acetylcholine receptors: an overview on drug discovery. Expert Opin Ther Targets 13: 395-411, 2009

35. Hetenyi C and van der Spoel D: Blind docking of drug-sized compounds to proteins with up to a thousand residues. FEBS Lett 580: 1447-1450, 2006

36. Iorga B, Herlem D, Barre E and Guillou C: Acetylcholine nicotinic receptors: finding the putative binding site of allosteric modulators using the 'blind docking' approach. J Mol Model 12: 366-372, 2006

37. DeLano WL: The PyMOL Molecular Graphics System. DeLano Scientific, San Carlos, CA, http://www.pymol.org., 2002.

38. DeLano WL: The case for open-source software in drug discovery. Drug Discov Today 10: 213-217, 2005.

39. http://www.genecards.org/cgi-bin/carddisp.pl?gene=PLAU\&rf $=/$ home/genecards/current/website/carddisp.pl\&ortholog $=$ all\# orthologs.

40. http://www.genecards.org/cgi-bin/carddisp.pl?gene=MMP9\&rf= /home/genecards/current/website/carddisp.pl\&ortholog=all\# orthologs.
41. Solsona E, Iborra I, Ricos JV, Monros JL, Casanova J and Dumont R: Effectiveness of a single immediate mitomycin C instillation in patients with low risk superficial bladder cancer: short and long-term followup. J Urol 161: 1120-1123, 1999.

42. Witjes JA: Current recommendations for the management of bladder cancer. Drug therapy. Drugs 53: 404-414, 1997.

43. Wang X, Lin YW, Wang S, et al: A meta-analysis of tea consumption and the risk of bladder cancer. Urol Int 90: 10-16, 2013

44. Wu S, Li F, Huang X, et al: The association of tea consumption with bladder cancer risk: a meta-analysis. Asia Pac J Clin Nutr 22: 128-137, 2013.

45. Lecumberri E, Dupertuis YM, Miralbell R and Pichard C: Green tea polyphenol epigallocatechin-3-gallate (EGCG) as adjuvant in cancer therapy. Clinical Nutr: Mar 15, 2013 (Epub ahead of print). pii: S0261-5614(13)00086-1. doi: 10.1016/j.clnu.2013.03.008, 2013.

46. Mak JC: Potential role of green tea catechins in various disease therapies: progress and promise. Clin Exp Pharmacol Physiol 39: 265-273, 2012

47. Shirakami Y, Shimizu M and Moriwaki H: Cancer chemoprevention with green tea catechins: from bench to bed. Curr Drug Targets 13: 1842-1857, 2012.

48. Yang CS and Wang X: Green tea and cancer prevention. Nutr Cancer 62: 931-937, 2010

49. Kamat AM and Lamm DL: Chemoprevention of bladder cancer. Urol Clin North Am 29: 157-168, 2002.

50. Maeda-Yamamoto M, Kawahara H, Tahara N, Tsuji K, Hara Y and Isemura M: Effects of tea polyphenols on the invasion and matrix metalloproteinases activities of human fibrosarcoma HT1080 cells. J Agric Food Chem 47: 2350-2354, 1999.

51. Demeule M, Brossard M, Page M, Gingras D and Beliveau R: Matrix metalloproteinase inhibition by green tea catechins. Biochim Biophys Acta 1478: 51-60, 2000.

52. Boehm K, Borrelli F, Ernst E, et al: Green tea (Camellia sinensis) for the prevention of cancer. Cochrane Database Syst Rev: CD005004, 2009.

53. Kim SJ, Jeong HJ, Lee KM, et al: Epigallocatechin-3-gallate suppresses NF-kappaB activation and phosphorylation of p38 MAPK and JNK in human astrocytoma U373MG cells. J Nutr Biochem 18: 587-596, 2007.

54. No JH, Jo H, Kim SH, et al: Expression of MMP-2, MMP-9, and urokinase-type plasminogen activator in cervical intraepithelial neoplasia. Ann NY Acad Sci 1171: 100-104, 2009.

55. Racioppi M, Porreca A, Foschi N, Delicato G, Destito A and D'Addessi A: Bladder perforation: a potential risk of early endovesical chemotherapy with mitomycin C. Urol Int 75: 373-375, 2005.

56. Zang Z, Xu H, Yu L, et al: Intravesical immunotoxin as adjuvant therapy to prevent the recurrence of bladder cancer. Chin Med J 113: $1002-1006,2000$ 